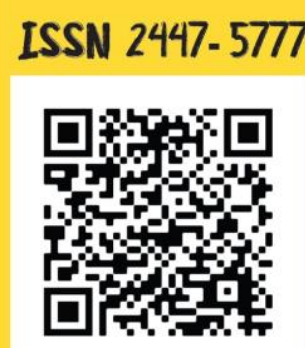

$\varepsilon$

$\mathbf{M}$

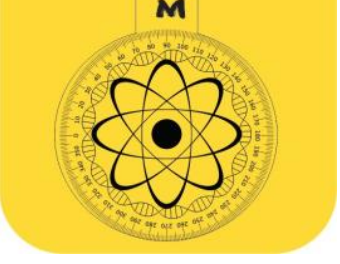

MULTIDISCIPLINARIDADE

Jul. | Dez. 2021 - Volume 7, Número 2, p. 53-64.

\title{
Intercâmbio intelectual, formação de professores e programas escolares: Alda Lodi, expert
}

\author{
Cultural exchange, teacher training and school programs: Alda Lodi, expert
}

\section{Ana Cristina Santos Matos Rocha ${ }^{1}$ - https://orcid.org/0000-0001-5718-1293}

${ }^{1}$ Doutora, Fundação Oswaldo Cruz (FIOCRUZ). Pesquisadora de pós-doutorado, Fundação Oswaldo Cruz (FIOCRUZ), Rio de Janeiro, Rio de Janeiro, Brasil. E-mail: anasmrocha@gmail.com

\section{Resumo}

Este artigo procura examinar a trajetória de Alda Lodi, enfocando o modo como sua atuação, no campo do ensino de matemática, consolidou seu papel de expert da educação em Minas Gerais. Formada na Escola Normal de Belo Horizonte, Lodi viajou aos Estados Unidos em 1927 como parte de uma missão pedagógica vinculada à reforma Francisco Campos. Sua viagem de estudos ao Teachers College funcionou como elemento de ascensão profissional, ao mesmo tempo em que fundamentou as discussões que ela desenvolveu com as professoras-alunas da Escola de Aperfeiçoamento de Belo Horizonte, onde foi professora de Metodologia da Aritmética. Neste artigo, procuramos explorar suas contribuições para o ensino de matemática a partir dos programas de Aritmética e Geometria do ensino primário - escritos por ela para a Secretaria de Educação de Minas Gerais entre os anos de 1941 e 1953. Com isso, procuramos contribuir para os estudos que investigam o papel que os experts desempenharam na sistematização de saberes a e para ensinar matemática no Brasil.

Palavras-chave: História da educação matemática. Alda Lodi. Experts. Programas de ensino.

\begin{abstract}
This article aims to examine Alda Lodi's career, focused on the way her work in the field of mathematics education helped to place her as an education expert in Minas Gerais. Alda Lodi graduated at the Belo Horizonte Normal School in 1915. In 1927, she travelled to the United States to study education as part of a pedagogical mission organized by Francisco Campos, who was reforming the education system of Minas Gerais state. Her time at the Teachers College, Columbia University was very important to her career. It also played a central role in the discussions developed by her at the Escola de Aperfeiçoamento de Belo Horizonte (Belo Horizonte Teacher Training School, in free translation), in the field of Methodology of Arithmetic. In this article we are going to explore her contributions to the teaching of mathematics using two Arithmetic and Geometry programs she wrote between the 1940's and 1950's for the Minas Gerais Department of Education. Thus, we aim to contribute to the
\end{abstract}

Como citar: ROCHA, A. C. S. M. Intercâmbio intelectual, formação de professores e programas escolares: Alda Lodi, expert. Ensino \& Multidisciplinaridade, São Luís (MA), v. 7, n. 2, p. 53-64, 2021. 
studies that deal with the role played by experts in the systematization of the knowledge to teach and for teaching in the field of mathematics education in Brazil.

Keywords: History of mathematics education. Alda Lodi. Experts. Teaching Programs.

\section{Introdução}

Este artigo examina a trajetória profissional de Alda Lodi, enfocando o modo como sua atuação, no campo do ensino de matemática, consolidou seu papel de expert da educação em Minas Gerais. Normalista, formada pela Escola Normal Modelo de Belo Horizonte em 1915, Lodi atuou como professora do ensino primário nesta mesma instituição. Depois de cerca de dez anos atuando neste nível do ensino, viajou aos Estados Unidos como parte de uma missão pedagógica vinculada à reforma Francisco Campos. Entre 1927 e 1929, Lodi especializou-se em Metodologia da Aritmética no Teachers College da Universidade de Columbia, em Nova Iorque, embora tenha voltado sem certificação dos estudos que lá desenvolveu. Sua temporada de formação no Teachers College funcionou como elemento de ascensão profissional, ao mesmo tempo em que fundamentou as discussões que ela desenvolveu com as professorasalunas da Escola de Aperfeiçoamento de Belo Horizonte, onde foi professora de Metodologia da Aritmética.

Diversos trabalhos exploraram o modo como Alda Lodi foi uma personagem relevante para o campo do ensino de matemática em Minas Gerais. Estes trabalhos também procuraram apontar as interseções que podem ser encontradas entre as aulas que Lodi assistiu no Teachers College e as aulas que ministrou em seu retorno ao Brasil (BARROS; OLIVEIRA, 2016; REIS, 2014; FONSECA et al., 2014; FONSECA, 2010, dentre outros). Em contrapartida, poucos são os registros escritos por ela que foram publicados e localizados pelas pesquisas já realizadas sobre esta educadora. A exceção fica por conta de um artigo reproduzido na Revista do Ensino intitulado "O cruzeiro na escola primária" (LODI, 1946; ROCHA, no prelo), em que ela trabalha o impacto da mudança do padrão monetário brasileiro - do mil réis para o cruzeiro em 1942 - para o ensino de matemática na escola primária. Além disso, dois dos programas de ensino primário de Aritmética e Geometria publicados pela Secretaria de Educação de Minas Gerais são de sua autoria (MINAS GERAIS, 1941, 1957).

Sempre lembrada como uma pessoa discreta e reservada, Alda Lodi teve tempo de receber, ainda em vida, homenagens que reconheciam o trabalho desenvolvido por ela neste estado. Em 1952 recebeu sua primeira homenagem: a "Medalha de honra da inconfidência" por "méritos cívicos". Em 1971, tornou-se professora emérita da Faculdade de Educação da UFMG. Em 1993, foi homenageada pela Assembleia Legislativa de Belo Horizonte e, em 1997, recebeu a comenda Lúcia Casassanta (APAL, envelope 51).

Assim, a importância de Alda Lodi para a educação em Minas Gerais foi reafirmada tanto pela historiografia da educação quanto pela sociedade em seu sentido mais amplo. É possível que o alcance de suas aulas tenha ultrapassado as fronteiras mineiras. Como professora da Escola de Aperfeiçoamento de Belo Horizonte, recebeu professores de outros estados nos cursos que ali ministrava, estes enviados por suas respectivas secretarias de educação (KULESZA, 2019; BÚRIGO et al., 2020). Em fevereiro de 1939, Alda Lodi participou do curso de férias promovido pela Secretaria de Educação e Saúde da Bahia, ministrando aulas de Metodologia de Aritmética (ALVES, 1939, p. 25).

Em nosso artigo, mais do que reafirmar sua importância como educadora, nosso objetivo é examinar em que medida Alda Lodi pode ser tomada como uma expert em educação, elemento fundamental de mediação entre as políticas educacionais e as práticas pedagógicas. Para isso, 
vamos analisar o trabalho desenvolvido por Alda Lodi na Escola de Aperfeiçoamento de Belo Horizonte e as orientações para o ensino de Aritmética e Geometria veiculadas nos Programas de 1941 e 1953 (MINAS GERAIS, 1941, 1957). Antes, vamos examinar o próprio conceito de expert, refletindo sobre as particularidades dessa categoria. Assim, nossa contribuição será a de tomar a experiência de Lodi como um exemplo do modo como os experts participaram da elaboração de saberes matemáticos conectados ao exercício da docência.

\section{Expert, expertise e produção de saberes}

Esta pesquisa se insere dentro dos estudos que investigam a profissionalização das atividades do ensino, considerando os saberes que são próprios deste campo de atuação. Dentro desse leque amplo de atividades está a da docência, campo de tensão permanente entre os saberes dos campos disciplinares em que estes professores atuam e os saberes do campo das ciências da educação, que são parte da identidade profissional desses atores. Enquanto os primeiros são classificados como saberes $a$ ensinar, objeto do trabalho do professor, os segundos estão agrupados dentro dos saberes para ensinar, ferramentas que tornam esse trabalho possível (HOFSTETTER; VALENTE, 2017).

Seguindo essa lógica, as pesquisas que têm como foco a atuação do professor que ensina matemática, considera também a existência de uma matemática $a$ e para ensinar. Esses saberes se modificam historicamente, e são construídos em diálogo com outros elementos da cultura escolar: as instâncias de formação dos professores, as vagas pedagógicas, as legislações do ensino, dentre outros. Para Wagner Valente (2020, p. 167), mais do que uma matemática escolar, essa síntese dá origem a uma matemática do ensino, fruto do diálogo constante entre "a formação de professores e a docência propriamente dita".

Dentro desta configuração é que localizamos a figura do expert em educação, que se converte em ponte entre esses dois campos (o da formação e o da docência), num trabalho que traduz em termos práticos as inovações das teorias educacionais em circulação. No vocabulário de nossa bibliografia de referência, o expert participa de um processo de "sistematização" e "objetivação" de saberes que se tornam referência nestes espaços. Assim, atuando como elemento que opera dentro da tensão existente entre os saberes a e para ensinar, os experts produzem novos saberes para a formação e para docência (MORAIS; VALENTE, 2020). Do ponto de vista destes trabalhos, essa produção não é espontânea: ela está vinculada a uma demanda do estado - que se liga a existência de um problema prático a ser resolvido - e a convocação do expert para que este problema seja solucionado a partir de sua expertise. Este último está menos conectado a amplitude do conhecimento do expert do que à sua capacidade de oferecer um "produto" ou solução para o problema em questão.

Dito de outro modo, o expert seria um

personagem convocado para ocupar uma posição de poder relativamente à sistematização do saber para o ensino e para a formação docente, em um dado momento no qual as autoridades educativas necessitam realizar, por exemplo, uma reforma do ensino (VALENTE; MORAIS; BERTINI, 2021, p. 9-10).

No Brasil, a convocação estatal é central porque, ainda que as inovações tenham pontos de partida diverso, é a partir dela que o expert materializa suas ideias sobre o ensino em diretivas que terão um alcance amplo. Assim, as orientações presentes nos documentos que integram a legislação educacional - na qual estão inseridos os programas escolares - legitimam essas inovações, transformando-as em parte da política educacional vigente.

Esta conexão entre estado e expertise é especialmente relevante nos países em que - a exemplo do Brasil - o estado desempenha papel central na definição das políticas educacionais 
a serem adotadas. O mesmo acontece no caso suíço analisado por Hofstetter, Schneuwly e Freymond (2017) num processo que começa na segunda metade do século XIX. Nas palavras dos autores, quando ao estado "é confiado o direito e o dever de organizar um sistema escolar público coerente e completo, sob sua direção e financiamento [...] multiplicam-se as convocatórias de especialistas das questões educativas" (HOFSTETTER; SCHNEUWLY; FREYMOND, 2017, p. 61).

Para estes autores, a crescente autonomização do sistema público de ensino "cria simultaneamente instâncias de autorreflexão" nas quais a participação dos experts está inserida. Assim, a autonomização dos sistemas de educação e "institucionalização da expertise" são parte de um mesmo processo. É dentro de um quadro de transformação constante que estes autores vão se referir a ideia de "práticas de expertise", que estão conectadas ao contexto educacional com o qual dialogam (HOFSTETTER; SCHNEUWLY; FREYMOND, 2017, p. 104).

Considerando essas concepções, argumentamos que o caso de Alda Lodi nos parece um bom caminho para refletir sobre o modo como alguns educadores ocuparam a posição de experts do ensino. No contexto das décadas de 1920 e 1930, as viagens pedagógicas exercem um papel importante para as convocações estatais. Primeiro porque as experiências dos educadores em países estrangeiros foram convertidas em credencial para os postos que vão ser ocupados em seus retornos (MIGNOT; GONDRA, 2007). Depois porque um dos resultados esperados de suas viagens é que eles sejam capazes de traduzir as teorias e experiências educacionais dos países visitados, convertendo-as em princípios úteis ao desenvolvimento da educação nacional.

Essa apropriação do internacional e sua consequente adaptação ao local a partir de um processo que sintetiza nacional e estrangeiro é uma das marcas da atuação de educadores como Alda Lodi. Além dela, outras educadoras que exerceram papel relevante na configuração de uma matemática do ensino também se especializaram em educação nos Estados Unidos, a exemplo de Alfredina de Paiva Souza, Irene de Albuquerque, Ismael de França Campos e Rizza de Araújo Porto (VILLELA et al., 2016). Eles são parte integrante do processo de internacionalização do pensamento educacional que vinha se desenvolvendo desde o século XIX (MATASCI, 2016; VALENTE, 2017; MORAIS, 2018).

Deste modo, a viagem de Alda Lodi ao Teachers College da Universidade de Columbia exerce múltiplas funções em sua trajetória profissional. Primeiro é o lugar de sua especialização. Depois, torna-se credencial para sua atuação na Escola de Aperfeiçoamento de Belo Horizonte, como professora de Metodologia da Aritmética. Posteriormente, viagem e especialização serão parte das justificativas de sua convocação para integrar as comissões responsáveis por elaborar os programas do ensino primário de Minas Gerais. Entretanto, assim como ideias inovadoras não são o suficiente para caracterizar um educador como expert, a convocação do estado para ocupar cargos técnicos que envolvem a elaboração de diretivas do ensino também não funciona de forma isolada. É justamente na convergência entre demanda do estado e elaboração de um plano ou produto que atenda esta solicitação que encontramos a interseção em que atua o expert.

Dentro desse quadro de análise, consideramos que é importante explorar dois aspectos implicados na categorização de Alda Lodi como uma expert. O primeiro são as circunstâncias que justificaram a convocação de Alda Lodi para participar das comissões que elaboraram dois dos programas de ensino de Minas Gerais, que vigoraram entre os anos de 1941 e 1964 (MINAS GERAIS, 1941, 1957). O segundo são as orientações para o ensino de Aritmética e Geometria presentes nestes programas de Aritmética e Geometria, que sinalizam a expertise de Lodi. Diante disso, procuramos mostrar como Lodi estabeleceu diretrizes que dialogavam com múltiplas instâncias: sua formação no Teachers College, a formação que procurava dar às suas 
alunas da Escola de Aperfeiçoamento de Belo Horizonte e do Instituto de Educação de Minas Gerais, e com as sugestões que recebeu de professoras que atuavam em grupos escolares de Belo Horizonte, por intermédio da Secretaria de Educação de Minas Gerais.

\section{Os conteúdos convertidos em ação: o trabalho de Lodi na Escola de Aperfeiçoamento de Belo Horizonte}

Antes de examinar as circunstâncias que justificavam a viagem de estudos de quatro das cinco professoras que integraram a missão pedagógica idealizada por Francisco Campos, é preciso dizer que seus significados foram amplamente publicizados. Tanto a partida da missão mineira ao Teachers College, quanto o seu retorno, foram registrados nos jornais como parte do movimento de renovação da educação que se desenrolava no bojo da reforma implementada por Francisco Campos, durante o governo de Antônio Carlos Ribeiro de Andrada. Alda Lodi, Lúcia Casassanta, ${ }^{1}$ Amélia de Castro Monteiro e Benedicta Valladares Ribeiro foram aos Estados Unidos para conhecer e estudar as inovações pedagógicas que estavam sendo experimentadas naquele país. Cabia a elas ajudar a renovar os métodos de ensino adotados pelos professores de Minas Gerais a partir de uma instituição que começaria a funcionar a partir de 1929, quando retornariam: a Escola de Aperfeiçoamento de Belo Horizonte (EA). Liderando a missão, Ignácia Guimarães havia recebido bolsa de estudos do Teachers College. Não partiu, portanto, com o compromisso de atuar em uma instituição específica em seu retorno. Das quatro professoras que viajaram financiadas pela secretaria de educação, apenas Benedicta Ribeiro atuou em outra instituição: a Escola Normal de Belo Horizonte (FONSECA, 2010).

A Escola de Aperfeiçoamento desempenhou um papel estratégico na reforma de Campos porque enfocava a formação de profissionais que já atuavam no ensino público mineiro. Em teoria, as normalistas que se especializavam na EA deveriam trabalhar como técnicas de ensino em suas escolas de origem, funcionando como agentes de difusão das orientações que receberam nesta instituição (PRATES, 1989). Deste modo, a reforma idealizada por Campos pretendia alcançar não só a formação de novos professores, mas também a atuação de professores que foram formados a partir de outras correntes pedagógicas. Além da missão que viajou aos Estados Unidos, a EA contou com professores europeus, recrutados por Alberto Álvaro Campos - irmão de Francisco Campos - para auxiliar na implementação da reforma. Destes, permaneceram como professores da EA, a psicóloga russa Helena Antipoff e a escultora belga Jeanne Louise Milde (KULESZA, 2019).

Embora a viagem ao Teachers College não tenha definido a posição que Alda Lodi, Lúcia Casassanta e Amélia de Castro Monteiro iriam ocupar no campo educacional, ela contribuiu para estabelecer as áreas de atuação pelas quais elas ficariam associadas ao longo de suas trajetórias profissionais. A partir do trabalho na EA, ficaram conhecidas pelas disciplinas que ministraram e tiveram espaço para testar as inovações que estudaram nos Estados Unidos. Junto com as professoras-alunas da EA, realizaram experiências com alunos dos grupos escolares de Belo Horizonte e das classes anexas da própria EA, que muitas vezes funcionou como um espaço para entender as peculiaridades da população escolar de Minas Gerais.

No caso de Alda Lodi, duas dessas experiências ficaram registradas na Revista do Ensino. A primeira é mencionada por ela no "Curso para o professorado primário" ministrado em abril de 1930. De acordo com o resumo do curso publicado na revista, na sexta aula do curso de Metodologia da Aritmética,

\footnotetext{
${ }^{1} \mathrm{Na}$ época da viagem, ainda solteira, chamava-se Lúcia Schmidt Monteiro de Castro.
} 
a professora Alda Lodi referiu-se às experiências feitas no ano passado, sob sua direção, pelas alunas da Escola de Aperfeiçoamento, com referência à subtração. 895 crianças foram testadas em três casos desta operação [...] (REVISTA DO ENSINO, 1930, p. 45).

O objetivo da experiência era o de indicar o grau de dificuldade de operações que incluíam "dois termos representados por números diferentes" ( $1^{\circ}$ tipo), "dois termos iguais" ( $3^{\circ}$ tipo) ou ainda uma subtração em que "o segundo termo era zero" ( $2^{\circ}$ tipo) (REVISTA DO ENSINO, 1930, p. 45). Além de ajudar suas alunas a entender a dificuldade que os alunos teriam com o conceito de zero, era a partir de experiências como essas que Alda Lodi demonstrava o fundamento das orientações metodológicas que dava em seus cursos. Com isso, Lodi também se inseria dentro da modernidade pedagógica que tinha nas experiências de testagem um de seus fundamentos (PINHEIRO, 2017). Assim, imbuída da experiência de formação nos Estados Unidos, Alda Lodi refletia sobre o ordenamento dos conteúdos a serem ministrados aos alunos das escolas mineiras.

Em 1946, em artigo também publicado na Revista do Ensino, Alda Lodi explorava outra experiência realizada nas classes primárias da EA. No ano de 1942, o governo brasileiro determinou a mudança do padrão monetário para o cruzeiro em lugar do antigo mil réis. Em seguida, o Departamento de Educação recomendou que o novo padrão monetário fosse adotado nas aulas do terceiro e quarto anos do ensino primário. Considerando que seria útil entender o impacto da mudança no ensino de matemática, Alda Lodi assim descreve a experiência que realizou:

\footnotetext{
Entregamos às classes primárias de $3^{\circ} \mathrm{e} 4^{\circ}$ anos, anexos à Escola de Aperfeiçoamento, um pequeno questionário, a que chamamos de 'Jogo do Cruzeiro'. Para as crianças, com a finalidade de saber 'quem estaria preparado para fazer transações a partir de $1^{\circ}$ de novembro'. E para nós: a finalidade de descobrir as dificuldades que a moeda traria ao aprendizado, um trabalho de diagnóstico e indicador, talvez, de diretrizes para o futuro (LODI, 1946, p. 34).
}

A partir desta experiência, Lodi concluiu que era importante começar o trabalho com números decimais antes do que determinava o programa em vigor, além de identificar as dificuldades que os alunos tinham na escrita da nova moeda. Tanto este caso quanto o anterior (em que trabalhou com operações de subtração) sinalizam parte do processo de elaboração de uma matemática do ensino, em que Lodi discute aspectos de uma matemática para ensinar.

Embora só tenhamos localizado dois registros de experiências que tinham como objetivo entender dinâmicas específicas do aprendizado de matemática, é possível inferir que elas não foram isoladas. A Escola de Aperfeiçoamento tinha como uma de suas premissas a realização de testes como estes, que ajudariam a entender como as teorias educacionais funcionavam em interação com o perfil dos alunos de Minas Gerias. Muitas dessas experiências foram coordenadas por Helena Antipoff, diretora do Laboratório de Psicologia da EA (KULESZA, 2019). De todo modo, é importante ressaltar que, mais do que defender métodos de ensino baseado em leituras estrangeiras, Alda Lodi procurou ensiná-los considerando as particularidades do ensino em Minas Gerais, o que sinaliza uma das dimensões de sua apropriação dos princípios discutidos no Teachers College.

Se essas experiências sinalizam parte desse processo de apropriação, os cadernos e trabalhos das alunas de Lodi depositados em seu arquivo pessoal nos apontam outra dimensão. Uma vez que Alda Lodi ministrava aulas para professoras que tinham experiência docente nas classes das mais diversas regiões do estado, é de se esperar que parte das particularidades dos alunos mineiros a que nos referimos aqui fosse levantada por estas mesmas professoras. Por 
isso, na EA, Lodi teve a oportunidade de dimensionar a pertinência dos métodos de ensino por ela discutidos em diálogo com profissionais que refletiram sobre as questões por ela apresentadas baseadas em suas práticas de ensino.

Em sua tese de doutorado, Diogo Reis (2014) explora algumas das discussões que ajudavam a materializar ideias mais gerais como a de que era preciso conectar o ensino à vida dos alunos. De acordo com o autor, no caderno de Imene Guimarães "os registros apresentam exemplos explicativos retirados dos contextos econômicos e socioculturais das cidades mineiras de Cachoeira do Campo e Muzambinho, buscando estabelecer elos com as experiências das crianças" (REIS, 2014, p. 217).

Os exemplos discutidos consideravam a inexistência de trens em Cachoeira do Campo e a existência de uma vinícola em Muzambinho para explorar como a ideia de problemas "reais" - termo frequentemente utilizado nos programas de ensino que vamos analisar a seguir - estava firmemente conectada aos contextos locais. Embora os dois exemplos possam ter sido trazidos pela própria Alda Lodi, o contato com professoras de diferentes partes do estado nos parece um dado que não pode ser desprezado em nossa reflexão sobre o trabalho que ela desenvolveu no campo do ensino de matemática.

\section{As convocações e os programas de Aritmética e Geometria do Ensino Primário}

Enquanto Alda Lodi estava no Teachers College, um novo programa para o ensino primário foi aprovado pelo decreto $\mathrm{n}^{\circ} 8.094$ de 22 de dezembro de 1927, e entrou em vigor no ano seguinte (MINAS GERAIS, 1928). Este programa trazia as marcas da renovação do ensino que Francisco Campos pretendia implementar em Minas Gerais. Como exemplo, podemos apontar as recomendações para aulas seguindo o método Decroly, a necessidade de valorizar a experiência infantil e a ideia do "aprender fazendo, da Escola Ativa" (MINAS GERAIS, 1928, p. 1558). Deste modo, quando retorna ao Brasil em 1929, Alda Lodi, já especialista, ainda não atua como expert em seu sentido mais estrito. A tarefa de estruturar a formação da Escola de Aperfeiçoamento e, no seu caso específico, refletir sobre o currículo da disciplina de Metodologia da Aritmética, é parte do caminho que a credencia para as convocações que virão posteriormente.

Antes de explorá-las, cabe ressaltar que, o nome de Alda Lodi não aparece no Programa de Ensino Primário publicado em 1941, que não menciona nenhum dos membros da comissão que elaborou o documento (MINAS GERAIS, 1941). Já no Programa do Ensino Elementar de 1953, o nome de Alda Lodi aparece como membro da comissão organizadora do programa de Aritmética e Geometria do documento (MINAS GERAIS, 1957, p. 7). Os documentos que nos deixam inferir que Lodi participou da elaboração do programa de 1941 estão presentes em seu arquivo pessoal. O primeiro é a presença desta informação em duas versões de seus currículos. Na primeira, uma observação manuscrita: "os atuais programas de Arit. e Geometria (curso primário), o de "Princípios Gerais de Educação" e "Metodologia da Arit. e Geometria" (da Escola de Aperf.) foram feitos por mim. Há lugar para estes trabalhos? Onde?” (APAL, envelope 39a).

Na segunda versão, esta informação já está datilografada: "organizadora dos programas de Aritmética e Geometria do ensino primário, atualmente em vigor no estado" (APAL, envelope 39a). Além disso, três versões datilografadas do texto introdutório do programa de Aritmética e Geometria de 1941 também foram localizadas em seu arquivo pessoal por Diogo Reis (2014). O título do documento também coincide com o título da introdução de 1941: "Aritmética e Geometria: considerações sobre o ensino de Aritmética e da Geometria no curso primário” (MINAS GERAIS, 1941, p. 87; REIS, 2014, p. 84). De acordo com Reis, 
Uma [versão], que acreditamos ser a primeira, foi datilografada em azul e apresenta diversos rabiscos e anotações manuscritas ao longo das páginas. A outra versão representa o mesmo documento, datilografado também em azul e preto, porém já incorpora as alterações que haviam sido escritas à mão na primeira versão. Por fỉm, encontramos uma terceira versão, cópia da segunda versão (REIS, 2014, p. 84).

Ao que parece, estes documentos fazem parte do processo de revisão que Lodi fez do programa publicado em 1941, do qual o programa de 1953 é resultado. Deste modo, embora a participação de Lodi na elaboração de um programa para o ensino primário só esteja explicitamente mencionada no segundo programa, de 1953, acreditamos que ela também participou da elaboração do programa anterior, de 1941.

Este não foi o primeiro trabalho técnico que teve a participação de Alda Lodi. Em 1932, Alda Lodi foi nomeada membro da seção técnica do Conselho Superior de Instrução de Minas Gerais (Jornal do Comércio, 12/06/1932). Em 1936, seu nome foi citado por Gustavo Capanema como uma das colaboradoras que ajudou a elaborar o inquérito que serviria de subsídio para o Plano Nacional de Educação (“O inquérito...”, 1936). ${ }^{2}$ Em 1937, elaborou o programa de Aritmética e Geometria da Escola de Aperfeiçoamento, como mencionado em seu currículo. Sem deixar de reconhecer a dimensão política das indicações para comissões encarregadas de elaborar os programas de ensino, é possível inferir que foi também com base nessas experiências profissionais que Alda Lodi foi um dos nomes escolhidos para integrar a equipe que elaborou os programas de 1941 e 1953.

No ano de 1941, a ideia veiculada pela Secretaria de Educação era que o "Programa em experiência" fosse tomado como orientações que deveriam ser testadas pelos professores. Ele deveria conciliar "as condições escolares atuais - composição média das classes, extensão do curso, duração do ano letivo e do dia escolar com significação social dos conhecimentos, hábitos, atitudes e ideias que à escola cabe desenvolver" (MINAS GERAIS, 1941, p. 319-320). Em termos contextuais, este programa foi editado em meio à ditadura do Estado Novo, num momento em que o investimento em educação feito pelo estado de Minas Gerais havia diminuído significativamente em relação ao ano de 1928, data de publicação do programa que o precedeu (PEREIRA, 2006). Considerando que o problema da repetência era significativo, o programa diminuiu a carga de conteúdos do primeiro ano primário. Com isso, esperavam resolver o problema dos alunos que chegavam a repetir quatro vezes esta série.

No caso do programa de Aritmética e Geometria, as orientações metodológicas ocupam espaço significativo. No Programa de 1928, onze tópicos orientavam o ensino de Aritmética e seis se referiam ao ensino de Geometria. Já o documento de 1941 explorava as finalidades do ensino dessas disciplinas, explicitando a importância dos problemas matemáticos para que os alunos entendessem a dimensão prática dos assuntos estudados. Embora o programa de 1928 mencionasse que um dos objetivos do curso primário era habilitar o aluno "a resolver os problemas elementares da vida prática” (MINAS GERAIS, 1928, p. 1586), o programa de 1941 fornecia exemplos concretos ao professor de como era possível transformar situações cotidianas em problemas a serem trabalhados em classe. Este detalhamento é uma característica deste programa, que também procura explorar os objetivos de aprendizagem de cada ano escolar.

No ano em que o programa foi publicado, a Revista do Ensino parou de ser editada em função da Segunda Guerra Mundial. Em 1946, o primeiro número que marca a retomada da revista, explica que dentre as consequências da segunda guerra, o encarecimento da mão-deobra e a possibilidade de importar papel de imprensa foram os principais motivos da interrupção

\footnotetext{
${ }^{2}$ De acordo com o documento, os outros membros da comissão foram: Lourenço Filho, Paulo de Assis Ribeiro, José Eduardo da Fonseca, Julio de Mesquita Filho, Almeida Junior, Paul Arbousse Bastide, Helena Antipoff, Benedicta Valadares e Noemi Silveira (“O inquérito...”, 1936, p. 202).
} 
das edições. De acordo com Maurilane Biccas, esta revista funcionou como espaço de orientação dos professores, encarados como "agente responsável pela implementação das diretrizes e das propostas educativas e pedagógicas que estavam sendo veiculadas pela Diretoria Geral de Instrução Pública, pela Inspetoria Geral de Instrução e, posteriormente, pela Secretaria de Educação" (BICCAS, 2008, p. 28).

No entanto, durante os cinco primeiros anos de vigência do programa de 1941, as orientações em relação às estratégias de execução das diretrizes deste documento não puderam ser discutidas via Revista do Ensino. Assim, o detalhamento do programa e suas orientações metodológicas tornavam-se ainda mais relevantes para os professores que atuavam no ensino primário de Minas Gerais. A partir desse programa, a secretaria de educação pôde oferecer a estes educadores uma orientação mais precisa em relação às finalidades e objetivos do ensino de matemática nos primeiros anos escolares, assim como exemplos que esclareciam como as prescrições poderiam ser colocadas em prática. Dito de outro modo, é também neste programa que encontramos indícios de uma matemática para ensinar pensada por Lodi para os professores de Minas Gerais.

Já o Programa do "Ensino Primário Elementar", publicado em 1953, era uma versão modificada do Programa de 1941. Parte das mudanças estavam ligadas ao contexto político do país, que havia voltado ao regime democrático. Outras mudanças partiam das críticas enviadas pelos professores à Secretaria de Educação, um plano que já estava explicitado no programa original. Algumas das cartas enviadas por professoras de dois grupos escolares de Belo Horizonte foram localizadas por esta pesquisa e estão presentes no arquivo pessoal de Alda Lodi (APAL, envelope 67). Esses documentos indicam que essas sugestões foram efetivamente enviadas pelas professoras, e recebidas por membros da comissão que elaborou o programa.

Na seção de Aritmética e Geometria, algumas modificações estavam relacionadas à divisão dos conteúdos, que voltaram a ser organizados por semestre. Outras estavam relacionadas à adaptação do ensino ao novo padrão monetário (cruzeiro), que entrou em vigor no ano de 1942. No programa de 1953, é possível identificar que Alda Lodi procurou esclarecer algumas passagens da introdução, agora intitulada "Aritmética e Geometria: considerações sobre o ensino" (MINAS GERAIS, 1957). Assim, era preciso também "situar exatamente aquelas noções que podem ser ensinadas em cada idade" e não apenas "oferecer aos alunos situações oportunas e atuais" para que eles pudessem compreender as relações numéricas (MINAS GERAIS, 1957, p.137). No trecho em que recomendava que os problemas apresentados aos alunos deveriam "acompanhar o desenvolvimento intelectual dos alunos", Lodi esclarecia que a dificuldade de solucionar um problema não era determinado pelo "número de operações" e sim pelas "relações entre os fatos do problema" (MINAS GERAIS, 1957, p. 139).

Ao que parece, estas mudanças não estavam apenas relacionadas às sugestões que Lodi recebeu dos professores que colocaram em ação as recomendações do programa de 1941. Enquanto professora da EA e do IEMG, Lodi teve a oportunidade de discutir com suas alunas aspectos do programa, o que pode ter contribuído para as modificações que realizou. Uma análise preliminar do caderno de uma de suas alunas do IEMG, Jacy Vasconcelos, indica que ela realmente discutiu a execução do programa em suas aulas, incluindo também atividades recomendadas pelo documento, como o uso da loja escolar no primeiro e no segundo anos (ROCHA, no prelo). Assim, foi em diálogo com suas alunas e com as sugestões recebidas que Alda Lodi sistematizou saberes de uma matemática $a$ e para ensinar, presente no Programa de 1953.

Por isso, além de elemento de consolidação profissional, a experiência de Lodi como professora formadora foi um dos fatores que contribuíram para a reflexão desenvolvida por ela 
na elaboração dos programas de ensino voltados para o nível primário. Ao identificar as dificuldades enfrentadas pelos professores, considerando-as em suas recomendações, Alda Lodi pôde selecionar os conteúdos adequados a cada um dos programas de ensino que ajudou a elaborar. Estes, por sua vez, são os produtos de sua expertise.

\section{De especialista à expert: algumas considerações}

Neste artigo, procuramos acompanhar a trajetória profissional de Alda Lodi, procurando ressaltar em que medida ela pode ser encarada como uma expert da educação em Minas Gerais. Os elementos que fundamentam essa afirmativa se relacionam à convocação estatal feita a Lodi para participar das comissões responsáveis pela elaboração dos programas escolares de 1941 e 1953, e aos conteúdos desses dois programas. Além da convocação, procuramos sinalizar como a expertise de Lodi, materializada nestas orientações curriculares, foi também produto de sua atuação como professora formadora na EA e na IEMG.

Mais do que especialista em Metodologia da Aritmética, Alda Lodi se apropriou dos conteúdos com os quais se familiarizou a partir de sua temporada de estudos e refletiu sobre o ensino de matemática em interação com as particularidades dos alunos e do sistema educacional de Minas Gerais. Ao transformar o debate que desenvolvia com as suas alunas - a partir de autores estrangeiros e brasileiros - em diretrizes para o ensino primário, Alda Lodi produziu novos saberes matemáticos. É neste sentido que argumentamos que a análise de sua trajetória é também o exame do processo de produção desses saberes, num movimento em que docência e reflexão sobre a prática docente estão em constante interação.

\section{Agradecimentos}

Este artigo é resultado da pesquisa financiada pela Fapesp (bolsa de pós-doutorado, processo n. 2019/04525-7) como parte do Projeto Temático do Ghemat-SP intitulado "A matemática na formação de professores e no ensino: processos e dinâmicas de produção de um saber profissional, 1890-1990" (processo n. 2017/15751-2).

\section{Referências}

ALVES, I. Educação e Saúde na Bahia na Interventoria de Landulpho Alves. Salvador, Bahia Graphica, 1939.

BARROS, S.; OLIVEIRA, M. C. A geometria na formação de normalistas mineiras em tempos de Escola Nova: referências e práticas de Alda Lodi. Histemat, v. 2, n. 2, 2016.

BICCAS, M. O impresso como estratégia de formação: Revista do Ensino de Minas Gerais (1925-1940). Belo Horizonte: Argumentum, 2008.

BÚRIGO, E. et al. Saberes Matemáticos nas Escolas Normais do Rio Grande do Sul (18891970). São Leopoldo: Oikos, 2020.

FONSECA, N. Alda Lodi, entre Belo Horizonte e Nova Iorque: um estudo sobre formação e atuação docentes 1912-1932. 2010. 159f. Dissertação (Mestrado em Educação) Universidade Federal de Minas Gerais, Belo Horizonte, 2010. 
FONSECA, N. et. al. O caderno de uma professora aluna e as propostas para o ensino de Aritmética na Escola Ativa (Minas Gerais, década de 1930). Hist. Educ., v. 18, n. 42, p. 9-35, 2014.

HOFSTETTER, R.; VALENTE, W. Saberes em (trans)formação: tema central da formação de professores. São Paulo, Livraria da Física, 2017.

HOFSTETTER, R.; SCHNEUWLY, B; FREYMOND, M. "Penetrar na verdade da escola para ter elementos concretos de sua avaliação" - a irresistível atuação do expert em educação (séculos XIX e XX). In: HOFSTETTER, R.; VALENTE, W. Saberes em (trans)formação: tema central da formação de professores. São Paulo: Livraria da Física, 2017.

KUlESZA, W. A. A Escola de Aperfeiçoamento de Belo Horizonte. Curitiba: Appris, 2019.

LODI, A. O cruzeiro na Escola Primária. Revista do Ensino, v. 14, n. 176, p. 33-39, 1946.

MATASCI, D. A França, a escola republicana e o exterior: perspectivas para uma história internacional da educação no século 19. Hist. Educ., v. 20, n. 50, p. 139-155, 2016.

MIGNOT, A. C.; GONDRA, J. G. Viagens Pedagógicas. São Paulo: Cortez, 2007.

MINAS GERAIS. Coleção de leis e decretos (1927) vol. III. Belo Horizonte, Imprensa Oficial, 1928. Disponível em: <https://dspace.almg.gov.br/handle/11037/4750>. Acesso em: 18 jul. 2021.

MINAS GERAIS. Programa em experiência (ensino primário). Belo Horizonte: Imprensa Oficial, 1941.

MINAS GERAIS. Programas (Ensino Primário Elementar). 2. ed. Belo Horizonte: Imprensa Oficial, 1957.

MORAIS, R. S.; VALENTE, W. R. Os Experts e o Saber Profissional do Professor que Ensina Matemática. Ciência \& Educação (Bauru), v. 26, 2020.

MORAIS, R. S. Experts. Cadernos de trabalho II, volume 6. São Paulo: Livraria da Física, 2018.

"O inquérito educacional". A Escola Primária: revista de educação, ano XIX, n. 10, 1936. Disponível em: <http://memoria.bn.br/DocReader/097497/5377>. Aceso em: 13 out. 2021.

PEREIRA, D. P. “Que arte entra na escola através do currículo?” Entre o utilitarismo e a possibilidade de emancipação humana pela arte, nos programas de 1928 e 1941, na Escola Nova em Minas Gerais. 2006. Dissertação (Mestrado em Educação) - Pontifícia Universidade Católica de Minas Gerais, Belo Horizonte, 2006.

PINHEIRO, N. A aritmética sob medida: a matemática em tempos da pedagogia científica. 2017. 223f. Tese (Doutorado em Educação e Saúde na Infância e na Adolescência) Universidade Federal de São Paulo, Guarulhos, 2017. 
PRATES, M. H. A introdução oficial do movimento de Escola Nova no Ensino Público de Minas Gerais. 1989. 206f. Dissertação (Mestrado em Educação) - Universidade Federal de Minas Gerais, Belo Horizonte, 1989.

REIS, D. História da formação de professores de matemática do ensino primário em Minas Gerais: estudos a partir do acervo de Alda Lodi (1927 a 1950). 2014. 258f. Tese (Doutorado em Educação) - Universidade Federal de Minas Gerais, Belo Horizonte, 2014.

REVISTA DO ENSINO, ano 5, n. 44, abril de 1930.

ROCHA, A. Interseções entre a formação de professores e a elaboração de Programas Escolares: Alda Lodi, Minas Gerais, 1941-1957. Perspectiva (no prelo).

VILLELA, L. M. et al. Os experts dos primeiros anos escolares: a construção de um corpo de especialistas no ensino de matemática. In: PINTO, N. B.; VALENTE, W. R. Saberes elementares matemáticos em circulação no Brasil. São Paulo: Livraria da Física, 2016.

VALENTE, W. R. A Matemática no Curso Primário: quando o nacional é internacional, França e Brasil (1880-1960). Bolema, v. 31, n. 57, p. 365-379, 2017.

VALENTE, W. R. História e cultura em educação matemática: a produção da matemática do ensino. REMATEC, v. 15, n. 36, p. 164-174, 2020. 